\title{
Assessing Quantitative Metrics of Transfer Film Quality as Indictors of Polymer Wear Performance
}

\author{
D.R. Haidar ${ }^{1}$, J. $\mathrm{Ye}^{2}$, A.C. Moore ${ }^{3}$, D.L. Burris ${ }^{13 *}$ \\ ${ }^{1}$ Department of Mechanical Engineering \\ University of Delaware \\ Newark, DE, United States \\ ${ }^{2}$ Institute of Tribology \\ Hefei University of Technology \\ Hefei, Anhui, China \\ ${ }^{3}$ Department of Biomedical Engineering \\ University of Delaware \\ Newark, DE, United States
}

\begin{abstract}
Reduced wear rates of filled polymeric tribomaterials consistently accompany improvements in the appearance of the transfer film, a protective layer of debris that adheres to the counterface. As a result, wear reductions are often attributed to the favorable effects of the filler on transfer film quality. However, the cause-effect relationship between fillers, transfer film quality, and polymer wear performance remains uncertain due, in part, to a lack of standard metrics for assessing transfer film quality. Methods for quantifying transfer film thickness and area fraction have been proposed previously; although some studies show strong correlations between these parameters and wear rate, others have demonstrated a lack of general applicability. In a more recent study, it was proposed that the characteristic size of the gaps in the transfer film (freespace length) may better reflect visual differences in transfer film quality and more directly relate to debris size and wear rate. In this paper, a representative collection of common tribological polymers and composites were subjected to wear testing and transfer film topology characterization to better generalize the link between polymer wear performance and transfer film topology (thickness, coverage, and domain size-scales). The free-space length provided the best correlation with steady state wear rates of the tribopolymers in this study; furthermore, the trendline from this study proved to be the best independent predictor of wear rates from previous studies. The results suggest that, among the metrics considered, the free-space length provides the best independent measure of transfer film quality in the context of polymer wear.
\end{abstract}

keywords: polymer tribology; transfer film; wear rate

*corresponding author

David L. Burris, Ph.D.

Dept. of Mechanical Engineering

University of Delaware

dlburris@udel.edu 


\subsection{Introduction}

Tribological polymers are typically composite materials designed to provide low friction and wear under unlubricated or otherwise challenging sliding conditions [1,2]. The inevitable wear of these materials generates debris that may either stick to the counterface or exit the tribological contact. When debris stick, they form a transfer film that protects the tribological polymer from further damage by the counterface [3-5]. Transfer films can be thick or thin, patchy or coherent, hard or soft, persistent or sacrificial [6-8]. If the transfer film is coherent and persistent, it becomes the relevant surface with which the tribological polymer interacts [2].

The hypothesis that improved transfer films better protect the polymer and thereby reduce wear is consistent with many observations in the literature. In 1996, Wang et al. [9] found that nanoscale $\mathrm{ZrO}_{2}$ significantly reduced the wear of polyetheretherketone (PEEK). Post-test scanning electron microscopy revealed that the transfer film of unfilled PEEK was 'thick, lumpy, and incoherent' while that of $\mathrm{ZrO}_{2}$-PEEK nanocomposite was 'thin, uniform, and coherent'. The group made similar observations in a study with nanoscale SiC in PEEK [10]; in this case they described the transfer films as 'thin, uniform, and tenacious' based on similar visual post-test observations of transfer films. In these and a series of other papers with nanofillers in PEEK, the authors attributed the tribological benefits of the nanofillers to improvements in the quality of the protective transfer films. Similarly, Li et al. [11] found that the addition of nanoscale $\mathrm{ZnO}$ to polytetrafluoroethylene (PTFE) reduced its wear rate while improving transfer film 'uniformity and tenacity'. Sawyer et al. [12] described the transfer films of low wear nanoscale alumina reinforced PTFE as 'well adhered, smooth, and continuous' and Bhimaraj et al. [13] found that filling polyethylene terephthalate (PET) with alumina reduced wear rates and produced more 'coherent and uniform' transfer films; Bahadur and Sunkara [14] described the transfer films of 2\%vol. nanoscale $\mathrm{CuO}$ filled and $\mathrm{TiO}_{2}$ filled polyphenylene sulphide (PPS) as 'thin and uniform'. Finally, McCook et al. [15] showed that more 'uniform' transfer films accompanied reduced wear of epoxy nanocomposites.

Although most previous studies characterize transfer films using qualitative descriptions of visual attributes (e.g. thick vs. thin, incoherent vs. coherent, etc.) [2], a number of more recent studies have attempted to define, quantify, and correlate morphological properties of transfer films to wear resistance of polymers or polymer composites. Burris and Sawyer [16] used 
profilometry to measure maximum transfer film thickness of different PTFE composites on surfaces of varying roughness and texture; they showed that the wear rate increased roughly with the cube of the transfer film thickness. Bhimaraj et al. [13] used optical measurements to quantify the area fractions of alumina-PET transfer films as a function of filler loading; not surprisingly, the area fraction tended to increase with increased filler loading and decreased wear rate. During dry sliding wear studies of PEEK in various configurations, Laux and Schwartz [17] showed that the testing configuration that produced the lowest wear rates also produced quantifiably thinner transfer films of greater area fractions. Finally, Rodriguez et al. [5] used dimensional analysis of transfer films for correlation to wear rates of PEEK-based composites.

Studies relating transfer films to polymer wear have been limited to steady state sliding using materials with a common polymer matrix with only a few exceptions. Ye et al. studied the evolution of an alumina-PTFE composite transfer film from run-in (high wear) to steady state (low wear) [18]. In their subsequent study, quantitative assessments showed that the 1,000x reduction in wear rate from run-in to steady state was accompanied by systematic changes in transfer film thickness, area fraction, and free-space length, which they defined as the characteristic size of the gaps in the films [19]. Thus, it appears that these relationships are not necessarily limited to steady state sliding conditions. However, under steady state conditions, Laux and Schwartz found that the correlation between wear rate and transfer film thickness [20] vanished when they varied the molecular weight and supplier of unfilled PEEK. To date, no single metric has emerged as an obvious choice for transfer film quality measurement. This paper attempts to test the link between wear rate and common measures of transfer film quality more generally using the broadest possible range of representative solid lubricant polymers.

\subsection{Material and Methods}

\subsection{Materials}

PTFE-based materials were made from Teflon ${ }^{\mathrm{TM}} 7 \mathrm{C}$ resin $(30 \mu \mathrm{m}$ reported diameter particles) from DuPont. PEEK-based materials were made from 450PF molding resin $(10 \mu \mathrm{m}$ reported diameter particles) from Victrex. Epoxy was prepared using Epon 828 resin from Momentive and 40 series anhydride curing agent from Lindride. Virgin polyethylene terephthalate (PET) 
from Ensinger's TECAPET®PET product line and polyphenylene sulfide (PPS) from Quadrant's Techtron ${ }^{\circledR P P S}$ product line were machined from bulk stock.

The $\alpha$-phase aluminum oxide filler had a reported diameter range of $27-43 \mathrm{~nm}$ but recent studies have revealed that the powders consisted primarily of relatively stable micron-scale agglomerates [21]. The $\gamma$-phase aluminum oxide nanoparticles were approximately equal to their reported size of $44 \mathrm{~nm}$ [22]. Both fillers were obtained from Nanostructured \& Amorphous Materials Inc. PTFE and PEEK nanocomposites contained 5\%wt. of either filler and were fabricated as described previously [16,21,23-25]. Briefly, the polymer matrix and nanofiller were pre-massed to prescribed amounts before being combined. One part of the powder ensemble was then added to two parts (volume) anhydrous ethanol and dispersed using an ultrasonic horn with $460 \mathrm{~W}$ power applied for two out of every three seconds over five total minutes. The powder mixture was then dried under rough vacuum at $100{ }^{\circ} \mathrm{C}$ and cold compacted in a cylindrical mold at $100 \mathrm{MPa}$ of pressure. The green sample was removed from the mold and heated in a nitrogen backfilled furnace using a ramp to $365^{\circ} \mathrm{C}$ in $3 \mathrm{~h}$, a $10 \mathrm{~h}$ hold at $365^{\circ} \mathrm{C}$, and a ramp to $50{ }^{\circ} \mathrm{C}$ in $3 \mathrm{~h}$.

Neat epoxy samples were fabricated using a resin to curing agent ratio of $54: 46 \%$ wt. The mixture was hand-stirred for 5 minutes and then poured into a rectangular $12 \mathrm{~mm} \times 12 \mathrm{~mm} \times 50 \mathrm{~mm}$ mold. The filled mold was kept in ambient conditions for 4 days before being placed into a furnace at $71{ }^{\circ} \mathrm{C}$ for $3 \mathrm{~h}$, then at $93{ }^{\circ} \mathrm{C}$ for $1 \mathrm{~h}$, and finally at $177{ }^{\circ} \mathrm{C}$ for $1.5 \mathrm{~h}$ at which point the sample was left to cool to room temperature within the oven.

These materials were chosen to reflect the most general possible cross-section of common tribological polymers within the literature including very high wear rate (PTFE [16]) and very low wear rate (PEEK-PTFE [26]) materials, a thermoplastic (PEEK [27]) and a thermoset (epoxy [15]) of comparable wear rates, and a range of relevant processing conditions (compression molding vs. extrusion for bulk stock).

Table 1. Glass transition temperature, melting temperature, and crystallinity of the polymer samples used in this study based on differential scanning calorimetry. PTFE has no thermallydetectable glass transition and epoxy does not melt. The glass transition of the PEEK-PTFE material was due to contributions from the PEEK. 


\begin{tabular}{cccc}
\hline material & $\begin{array}{c}\text { glass transition } \\
\text { temperature, } \\
\mathrm{T}_{\mathrm{g}}\left({ }^{0} \mathrm{C}\right)\end{array}$ & $\begin{array}{c}\text { melting } \\
\text { temperature, } \\
\mathrm{T}_{\mathrm{m}}\left({ }^{0} \mathrm{C}\right)\end{array}$ & $\begin{array}{c}\text { crystallinity, } \\
\mathrm{X}_{c}(\%)\end{array}$ \\
\hline PTFE & $\mathrm{N} / \mathrm{A}$ & 330 & 45 \\
$5 \%$ wt. $\gamma-\mathrm{Al}_{2} \mathrm{O}_{3}+\mathrm{PTFE}$ & $\mathrm{N} / \mathrm{A}$ & 330 & 45 \\
$5 \%$ wt. $\alpha-\mathrm{Al}_{2} \mathrm{O}_{3}+\mathrm{PTFE}$ & $\mathrm{N} / \mathrm{A}$ & 330 & 50 \\
32\%wt. PEEK + PTFE & 165 & 330 & 60 \\
PEEK & 155 & 345 & 35 \\
$5 \%$ wt. $\gamma-\mathrm{Al}_{2} \mathrm{O}_{3}+\mathrm{PEEK}$ & 150 & 355 & 40 \\
$5 \%$ wt. $\alpha-\mathrm{Al}_{2} \mathrm{O}_{3}+\mathrm{PEEK}$ & 155 & 340 & 40 \\
PET & 80 & 250 & 25 \\
PPS & 110 & 280 & 60 \\
Epoxy & 130 & N/A & N/A \\
\hline
\end{tabular}

\subsection{Wear rate quantification}

Each specimen was machined into a rectangular pin of $6.4 \mathrm{~mm} \times 6.4 \mathrm{~mm} \times 10 \mathrm{~mm}$ tall. A flat counterface of 304 stainless steel $38 \mathrm{~mm} \times 25 \mathrm{~mm} \times 3 \mathrm{~mm}$ was prepared by polishing and lapping to $15 \mathrm{~nm} \pm 5 \mathrm{~nm} R_{a}$. Wear tests were conducted on a linear reciprocating pin-on-flat tribometer previously reported in literature [18]. Before testing, each pin surface was preconditioned with $50 \mathrm{~N}$ of normal force (1.2 MPa pressure) against 600 grit $\mathrm{SiC}$ paper over 3 reciprocation cycles to remove machining marks, clean the surface mechanically, and align the surfaces within the tribometer as described by Ye et al. [18]. For each cycle a fresh region of grit paper was used and no subsequent cleaning was performed. Following abrasion, the dimensions and mass of the sample were measured with uncertainties of $\pm 0.05 \mathrm{~mm}$ and $\pm 0.05 \mathrm{mg}$, respectively.

Wear experiments were performed at a normal force of $250 \mathrm{~N}$ (6.3 MPa), a sliding speed of 50.8 $\mathrm{mm} / \mathrm{s}$, and a reciprocation length (half-cycle) of $25.4 \mathrm{~mm}$ in ambient laboratory conditions of $\sim 30 \%$ relative humidity and $\sim 25^{\circ} \mathrm{C}$. Testing was interrupted periodically to determine mass loss throughout each experiment [28]. The test was stopped when the sliding distance reached $8 \mathrm{~km}$ or when the volume lost exceeded $12 \mathrm{~mm}^{3}$. The steady state wear rate of the sample, $\mathrm{k}$ $\left(\mathrm{mm}^{3} / \mathrm{Nm}\right)$, was determined as described by Sawyer and Burris [28]. 


\subsection{Transfer film quantification}

A representative transfer film is shown in Figure 1. Images of each transfer film were collected at five locations (center and four corners) in the middle 50\% of the wear track (to eliminate effects of reversal zones) to obtain relevant statistics for transfer film attributes. A pixel was treated as polymer (transfer film) if there was clear evidence that it was the result of debris creation rather than film-drawing. This criterion is justified by the fact that PTFE, the standard for high wear, produces a thin, continuous, and likely persistent film (Figure 5a) beneath the thick and patchy debris-like transfer films described in the literature [29-31]. In most cases, pixel intensity thresholding was used to convert images into a binary image, i.e. black (polymer film) and white (free-space exposing counterface). In some cases, the distinction between transfer film and free-space was less obvious. In these cases, manual conversion was necessary using scanning electron microscopy (SEM) and optical microscopy (OM) to distinguish regions of polymer and counterface.

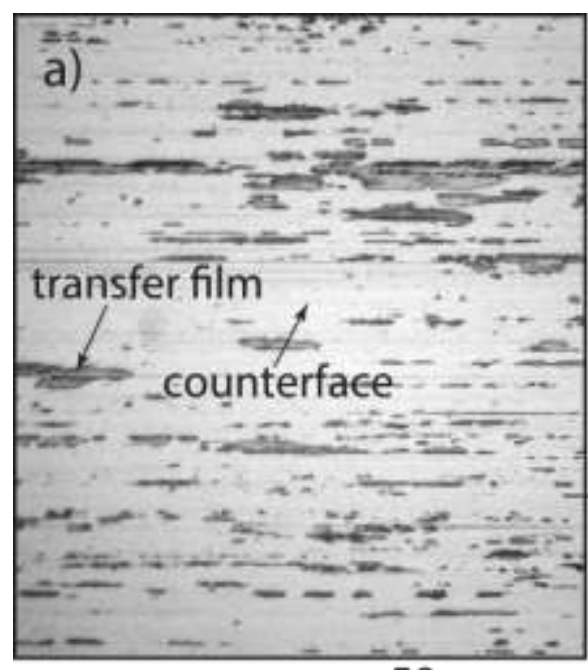

$50 \mu \mathrm{m}$
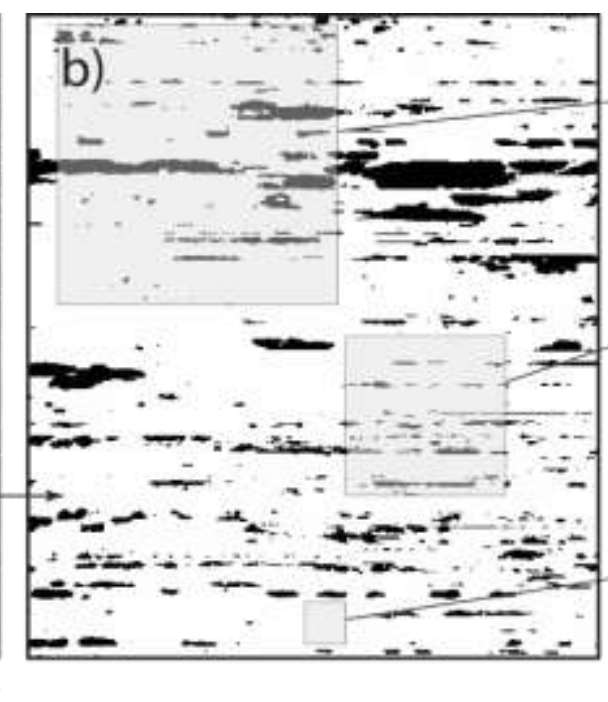

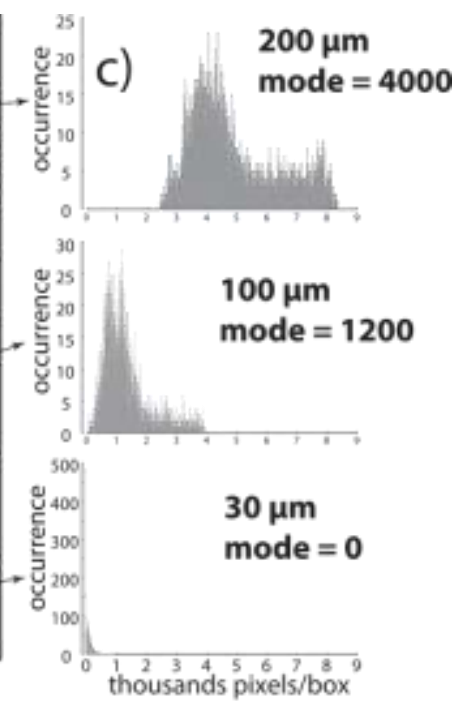

Figure 1. a) Optical image of a representative polymer transfer film illustrating regions of transferred polymer (dark) and bare counterface (light). b) Converted black and white image. In most cases, pixel intensity thresholding can be used to convert images into a processed black (polymer) and white (free-space) image. In some cases, manual conversion was required after complimentary tools (SEM and OM) were used to distinguish between polymer and free-space. Once converted, the images were used determine the free-space length using a custom code that determined the most likely number of intersecting black pixels in a randomly placed box of given size. The free-space length is the largest box size for which the most probable number of intersecting black pixels is zero. c) Illustrative histograms for this image for box widths of 200 , 
100, and $30 \mu \mathrm{m} ; 30 \mu \mathrm{m}$ is the free-space length of this image. Image adapted from [19] with permission.

A custom MATLAB ${ }^{\circledR}$ code from Ye et al. [19] was used to assess three distinct metrics of transfer film quality. First, the area fraction $(X)$ was determined as the ratio of black pixels to total pixels (20\% in Figure 1). The code then determines the free-space length $\left(L_{f}\right)$, which is defined as the characteristic size of the voids in the transfer film [19]. The code performs a Monte Carlo simulation to determine the probability of finding one or more pixels of transfer film within a randomly placed square of any fixed length; the free-space length is the largest square for which the most probable outcome is zero intersecting transfer film pixels. The process is illustrated by Figure 1c. The debris-space length $\left(L_{d}\right)$, which we define here as the characteristic size of continuous regions of transfer film, assesses the spatial characteristics of the transfer film rather than its gaps; this metric was included here to test a prevailing hypothesis that reduced wear and improved transfer film morphology are both natural consequences of debris size reduction $[3,16]$. The debris-space length was determined using the same procedure described above after inverting black and white colors of processed images. In other words, the free-space and debris-space lengths are the characteristic sizes of white and black domains in Figure 1b, respectively. The code and user's manual describing best practices can be obtained at: http://research.me.udel.edu/ dlburris/publicationsOther.html.

Measurements of film thickness used 1-D stylus profilometry with a soft (HDPE) large radius $(3.18 \mathrm{~mm})$ probe mounted to a $0.15 \mathrm{mN} / \mu \mathrm{m}$ cantilever as shown in Figure 2a. After leveling the counterface to $0 \pm 1 \mu \mathrm{m}$ per mm travel, the z-stage was used to apply a nominal initial contact force of $4 \mathrm{mN}$. The $\mathrm{z}$-stage was then fixed and the reciprocating stage was used to translate the sample at a speed of $0.3 \mathrm{~mm} / \mathrm{s}$. A calibrated displacement sensor $(100 \pm 0.014 \mu \mathrm{m})$ tracked the deflections of the probe as a function of position. Five $8 \mathrm{~mm}$-wide line scans were made across each $6.4 \mathrm{~mm}$-wide wear track at $0 \mathrm{~mm}$ (center), $\pm 3 \mathrm{~mm}$, and $\pm 6 \mathrm{~mm}$. Each line scan was individually tilt-corrected to the bare counterface on the sides of the wear track. Thickness was determined from these measurements using the method described by Laux and Schwartz [17]. All five tilt-corrected line scans for each sample were combined into a single 50-bin histogram and fit with a bi-Gaussian curve as shown in Figure 2c [17]. The reported transfer film thickness is the difference between the modes of the distributions; the uncertainty is the root sum square of 
the standard deviations.
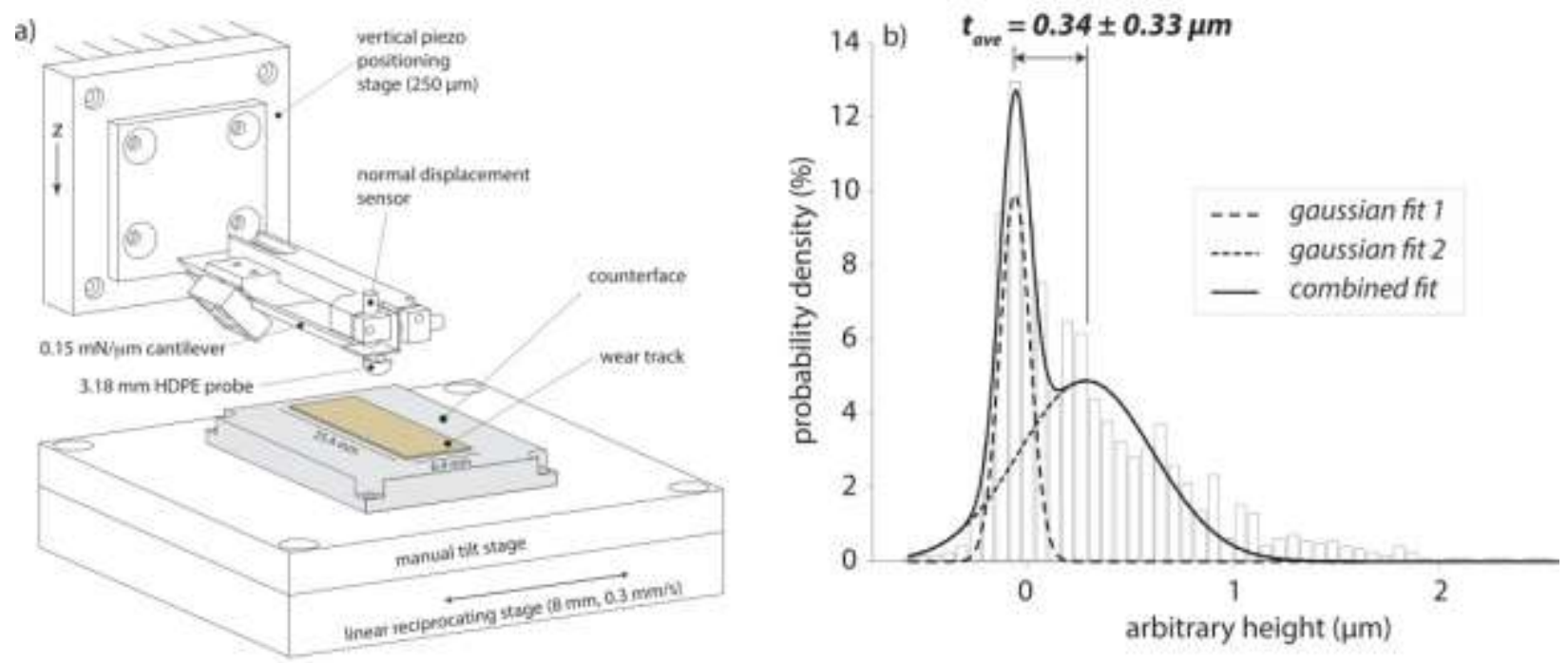

Figure 2. Schematic of the average transfer film thickness measurement using stylus profilometry. (a) A $6.35 \mathrm{~mm}$ diameter HDPE sphere was used to scan the transfer films perpendicular to the wear test sliding direction. The cantilever beam had a calibrated stiffness of $0.15 \mathrm{mN} / \mu \mathrm{m}$. (b) the histogram method of transfer film thickness quantification [17] applied to $N=5$ scans of the $5 \%$ wt. $\alpha$-phase alumina filled PTFE transfer film.

The non-traditional approach described above was needed to overcome several challenges we encountered during preliminary studies with more familiar methods. First, the histogram-based subtraction method, unlike the more typical 'inside versus outside' subtraction method $[24,25,32,33]$, is independent of area fraction. Second, although the large range of 1D profilometry ensures sufficient counterface for effective subtraction, purely 1D measurements of sparse 2D debris fields are unlikely to detect the representative peaks of interest (they mostly detect debris edges when they detect anything). Likewise, although 2D profilometry (e.g. SWLI and AFM) is ideal for sparse 2D debris fields, range limitations make counterface sampling difficult, especially in cases of high film coverage. We found that the hybrid approach taken here (large, soft 2D contact with 1D scan) largely solved these issues without the need for significant compromises. The large contact diameter $(\sim 50 \mu \mathrm{m})$ swept a wider sampling area and increased the likelihood of detecting the particle peaks rather than edges. The long span ensured detection of bare counterface on both ends of every scan regardless of coverage while maximizing leverage for leveling purposes. Because the deformation was dominated by the probe and not the 
film, there was no preferential deformation of the soft film relative to the hard counterface. Even with a permissible variation of $2 \mathrm{mN}$ (50\% the pre-load; due to tilt and film height), it can be shown that the resulting deformation-driven measurement error is less than $1 \%$; this error was far less than the control errors we observed when attempting to control load. Lastly, the low contact stress ( 1 MPa) and low surface energy of the HDPE probe virtually eliminated any potential for film damage; our previous study revealed that HDPE probes increased transfer film survival by $\sim 6$ orders of magnitude compared to probes of steel, glass, and other higher surface energy polymers under $1 \mathrm{~N}$ of load [8].

\subsection{Results}

The wear testing results are shown in Figure 3. Not surprisingly, PTFE had the highest wear rate of all polymers tested with $\mathrm{k}=6 \times 10^{-4} \mathrm{~mm}^{3} / \mathrm{Nm}$. PPS had the next highest wear rate with $\mathrm{k}=$ $1 \times 10^{-4} \mathrm{~mm}^{3} / \mathrm{Nm}$. The $5 \%$ wt. $\gamma$-phase alumina filled PTFE had a wear rate of $\mathrm{k}=5 \times 10^{-5} \mathrm{~mm}^{3} / \mathrm{Nm}$ and $\gamma$-phase alumina filled PEEK had a nearly identical wear rate of $\mathrm{k}=4 \times 10^{-5} \mathrm{~mm}^{3} / \mathrm{Nm}$. The wear rates of unfilled PEEK and epoxy were also nearly identical with $\mathrm{k}=1 \times 10^{-5} \mathrm{~mm}^{3} / \mathrm{Nm}$. The $\alpha$-phase alumina filled PEEK had the fourth lowest wear rate of $\mathrm{k}=1 \times 10^{-6} \mathrm{~mm}^{3} / \mathrm{Nm}$. PET was the most wear resistant unfilled polymer in the study with $\mathrm{k}=8 \times 10^{-7} \mathrm{~mm}^{3} / \mathrm{Nm}$. The $5 \%$ wt. $\alpha$ phase alumina filled PTFE had the second lowest wear rate of $\mathrm{k}=1 \times 10^{-7} \mathrm{~mm}^{3} / \mathrm{Nm}$ and the $30 \%$ wt. PEEK filled PTFE had the lowest wear rate in this study with $\mathrm{k}=4 \times 10^{-8} \mathrm{~mm}^{3} / \mathrm{Nm}$.

a)

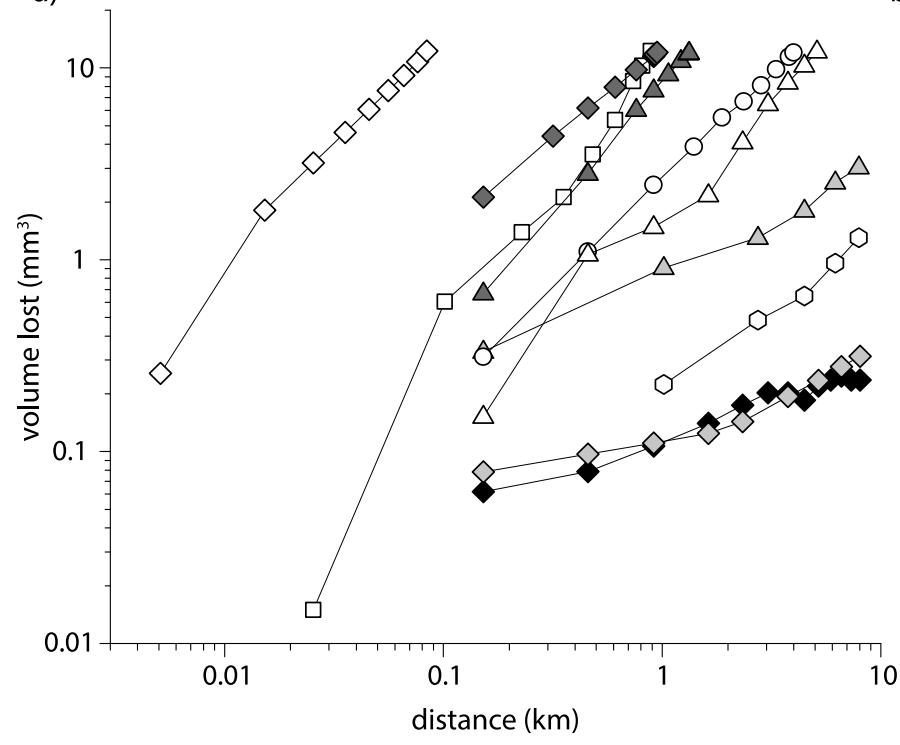

b)

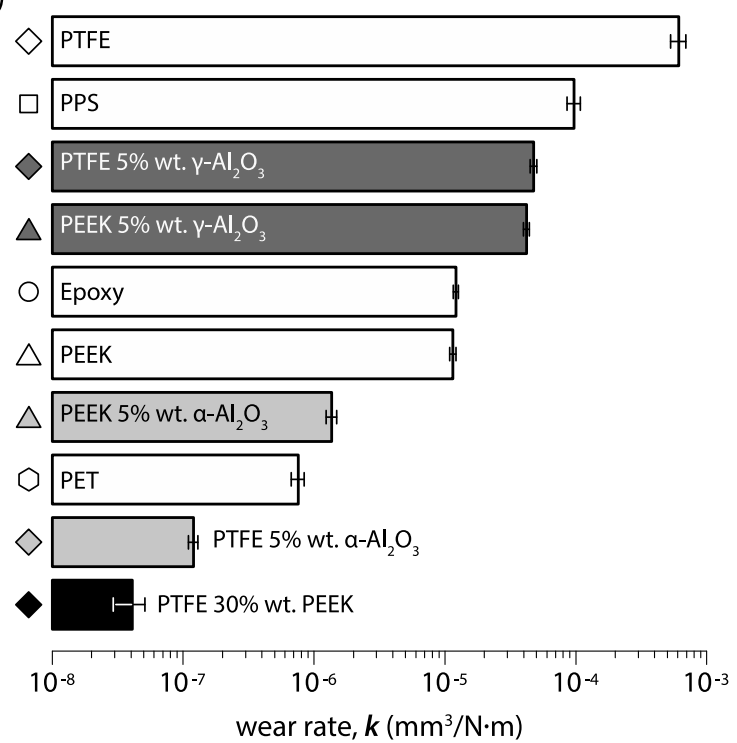


Figure 3. (a) Wear volume against sliding distance of all materials tested. Note that axes were necessarily logarithmically-scaled due to the wide variation in measured wear rates. (b) Steady state wear rates of all materials.

Representative images of the steady state transfer films produced by the tribological polymers in this study are shown in Figure 4; neat polymers are shown on the left and polymer composites are shown on the right, descending in order of decreasing wear rates. The visual morphologies of these transfer films are vastly different even among neat polymers ranging from thick and patchy (PTFE) to thin and patchy (epoxy) to thin and streaky (PEEK). Qualitatively speaking, decreasing wear rates were accompanied by increased area fractions and decreased debris size, thickness, and free-space length. These general trends agree well with the observations from more tightly controlled studies of a single polymer system [9-11,15,16,34-36]. 

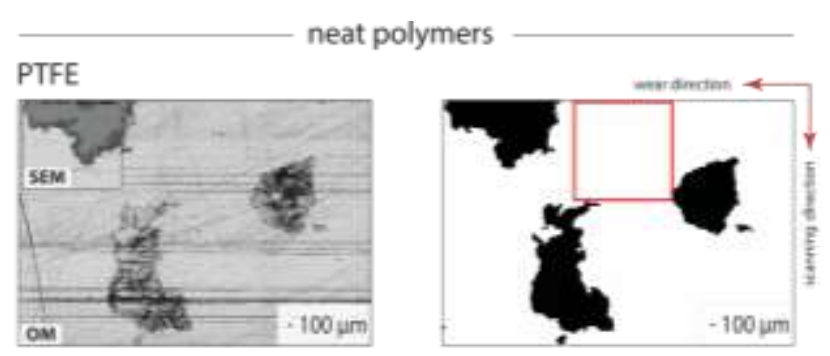

PPS
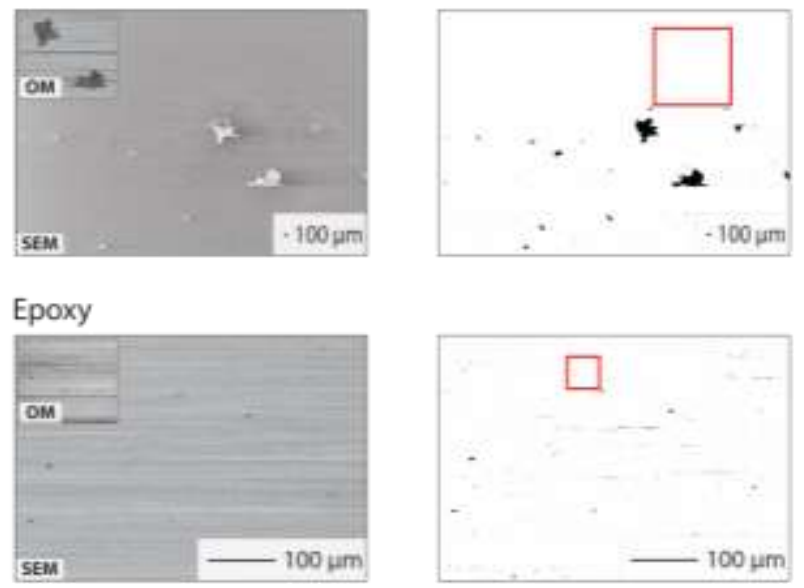

PEEK
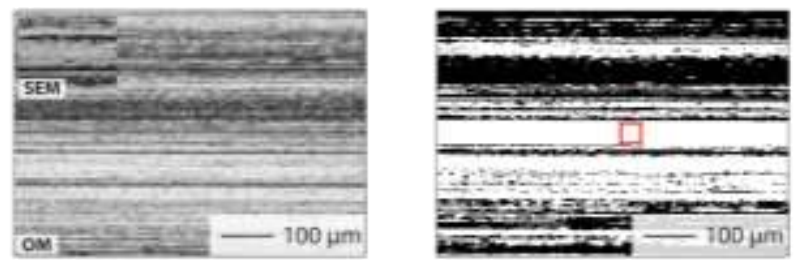

PET
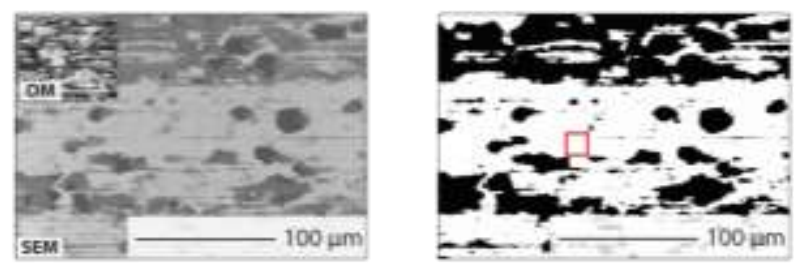
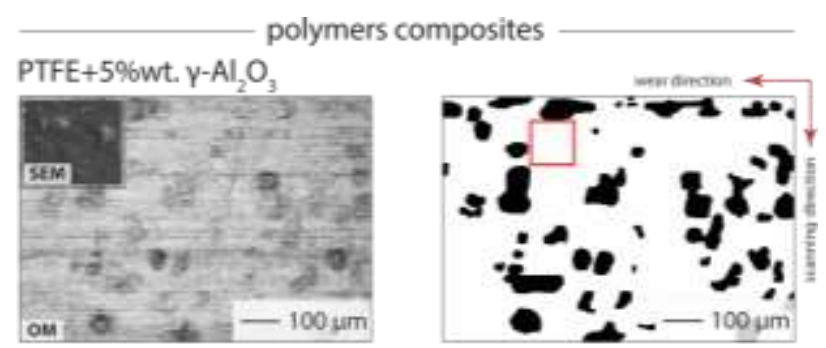

PEEK+5\%wt. $\gamma-\mathrm{Al}_{2} \mathrm{O}_{3}$
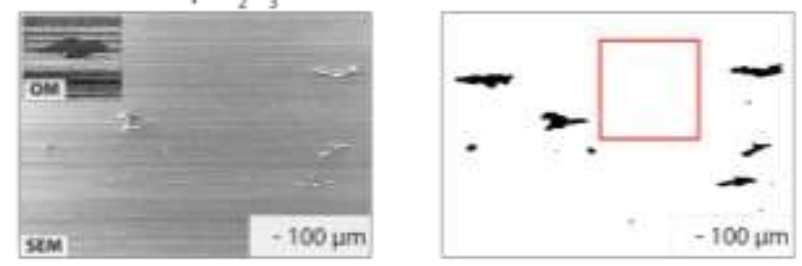

PEEK+5\%wt. $\mathrm{a}-\mathrm{Al}_{2} \mathrm{O}_{3}$
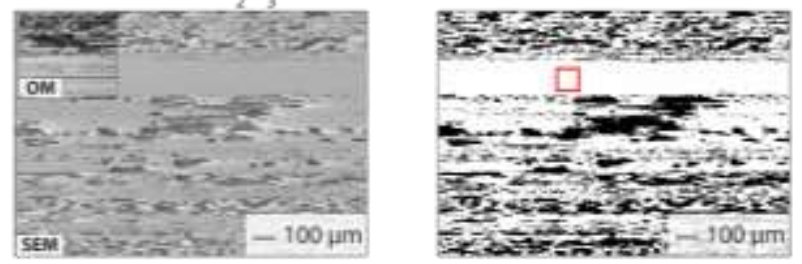

PTFE $+5 \% w t . a-\mathrm{Al}_{2} \mathrm{O}_{3}$
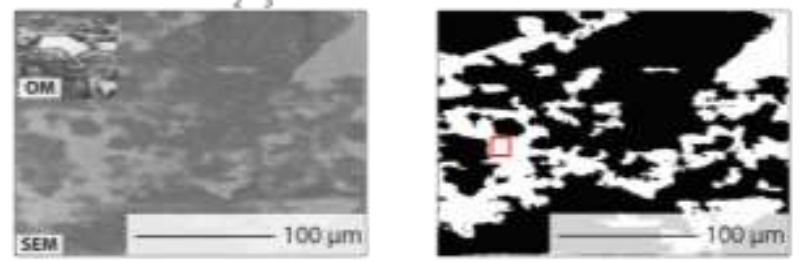

PTFE +30\%wt. PEEK
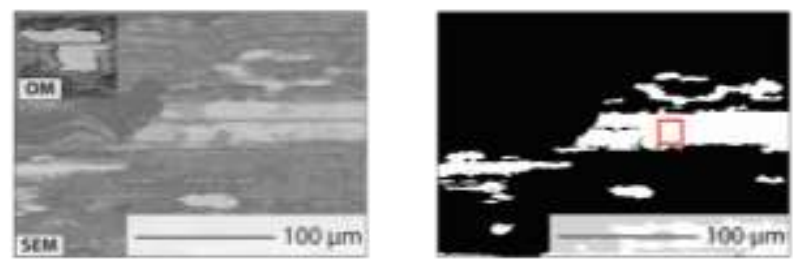

Figure 4. Representative images of all transfer films in the study with the corresponding image conversions. Neat polymers are shown on the left and polymer composites are shown on the right; samples in each column are organized by decreasing wear rate. Squares representing the mean free-space length of each transfer film is provided on each converted image to visually illustrate its relationship to the visual attributes of varying transfer films.

Table 2. The complete dataset from the study. The wear rate $(k)$, average thickness $\left(t_{\text {ave }}\right)$, transfer film area fraction $(X)$, free-space length $\left(L_{f}\right)$, and debris-space length $\left(L_{d}\right)$ are provided for each 
material. All values are reported as the mean \pm the standard deviation based on $N=5$ measurement locations for each sample.

\begin{tabular}{cccccc}
\hline material & $\begin{array}{c}k \\
\left(10^{-6} \mathrm{~mm}^{3} / \mathrm{Nm}\right)\end{array}$ & $\begin{array}{c}t_{\text {ave }} \\
(\mu \mathrm{m})\end{array}$ & $\begin{array}{c}X \\
(\%)\end{array}$ & $\begin{array}{c}L_{f} \\
(\mu \mathrm{m})\end{array}$ & $\begin{array}{c}L_{d} \\
(\mu \mathrm{m})\end{array}$ \\
\hline PTFE & $610 \pm 83$ & $1.9 \pm 0.4$ & $15 \pm 4$ & $2000 \pm 260$ & $580 \pm 81$ \\
PPS & $97 \pm 11$ & $0.5 \pm 0.3$ & $0.8 \pm 0.2$ & $1400 \pm 260$ & $41 \pm 10$ \\
5\%wt. $\gamma$ - $\mathrm{Al}_{2} \mathrm{O}_{3}+$ PTFE & $47 \pm 3$ & $1.3 \pm 1.0$ & $17 \pm 2$ & $110 \pm 16$ & $31 \pm 4$ \\
5\%wt. $\gamma-\mathrm{Al}_{2} \mathrm{O}_{3}+$ PEEK & $42 \pm 2$ & $0.2 \pm 0.2$ & $4 \pm 3$ & $1600 \pm 110$ & $94 \pm 19$ \\
Epoxy & $12 \pm 0.5$ & $0.5 \pm 0.2$ & $0.3 \pm 0.1$ & $48 \pm 13$ & $1 \pm 0.1$ \\
PEEK & $11 \pm 0.7$ & $0.3 \pm 0.2$ & $42 \pm 7$ & $34 \pm 9$ & $12 \pm 5$ \\
5\%wt. $\alpha$-Al ${ }_{2} \mathrm{O}_{3}+$ PEEK & $1.4 \pm 0.1$ & $0.6 \pm 0.3$ & $36 \pm 3$ & $96 \pm 14$ & $11 \pm 2$ \\
PET & $0.76 \pm 0.09$ & $0.6 \pm 0.3$ & $39 \pm 5$ & $15 \pm 3$ & $18 \pm 6$ \\
5\%wt. $\alpha-\mathrm{Al}_{2} \mathrm{O}_{3}+$ PTFE & $0.12 \pm 0.01$ & $0.3 \pm 0.3$ & $72 \pm 10$ & $13 \pm 5$ & $42 \pm 14$ \\
30\%wt. PEEK + PTFE & $0.04 \pm 0.01$ & $0.3 \pm 0.4$ & $72 \pm 18$ & $17 \pm 6$ & $48 \pm 29$ \\
\hline
\end{tabular}

Quantitative transfer film morphology data for each steady state film in this study are provided in Table 2; mean values are reported $\pm 95 \%$ confidence interval. The remarkably high wear rate of unfilled PTFE was associated with quantifiably thick transfer films $\left(t_{\text {ave }}=2 \mu \mathrm{m}\right)$ of low coverage $(X=15 \%)$, large free-space length $\left(L_{f}=2 \mathrm{~mm}\right)$, and large debris-space length $\left(L_{d}=0.5 \mathrm{~mm}\right)$. Transfer films from PPS, the next highest wear rate material in the study, had an average thickness of $0.5 \mu \mathrm{m}$, an area fraction of $1 \%$, a free-space length of $1.4 \mathrm{~mm}$, and a much smaller debris-space length of $40 \mu \mathrm{m}$. Transfer films from 5\%wt. $\gamma$-phase alumina-PTFE had an average thickness of $1.3 \mu \mathrm{m}$, an area fraction $17 \%$, a free space length of $110 \mu \mathrm{m}$, and a debris-space length of $30 \mu \mathrm{m}$. Despite performing comparably in wear testing, the transfer films of 5\%wt. $\gamma$ phase alumina PEEK were thinner $(t=0.2 \mu \mathrm{m})$ and less complete $(X=4 \%)$ with larger gaps $\left(L_{f}=\right.$ $1600 \mu \mathrm{m})$ and debris size $\left(L_{d}=90 \mu \mathrm{m}\right)$. The epoxy transfer film had an average thickness of 0.5 $\mu \mathrm{m}$, an area fraction of $0.3 \%$, a free-space length of $50 \mu \mathrm{m}$, and a debris-space length of $1 \mu \mathrm{m}$. The similarly wear resistant PEEK had a transfer film with an average thickness of $0.3 \mu \mathrm{m}$, an area fraction of $40 \%$, a free-space length of $30 \mu \mathrm{m}$, and a debris-space length of $12 \mu \mathrm{m}$. Transfer films of $5 \%$ wt. $\alpha$-phase alumina-PEEK, the next lowest wear rate material in the study, had an average thickness of $0.6 \mu \mathrm{m}$, an area fraction of $40 \%$, a free-space length of $100 \mu \mathrm{m}$, and a 
debris-space length of $11 \mu \mathrm{m}$. Transfer films of PET, the neat polymer in the study with the lowest wear rate, were $0.6 \mu \mathrm{m}$ thick, covered $40 \%$ of the area, contained $15 \mu \mathrm{m}$ gaps, and $20 \mu \mathrm{m}$ debris. The two low wear materials in the study (5\%wt. $\alpha$-phase alumina and 30\%wt. PEEK filled PTFE) produced quantitatively comparable transfer films with an average thickness of 300 $\mathrm{nm},>70 \%$ coverage, $<20 \mu \mathrm{m}$ gaps, and $<50 \mu \mathrm{m}$ debris.
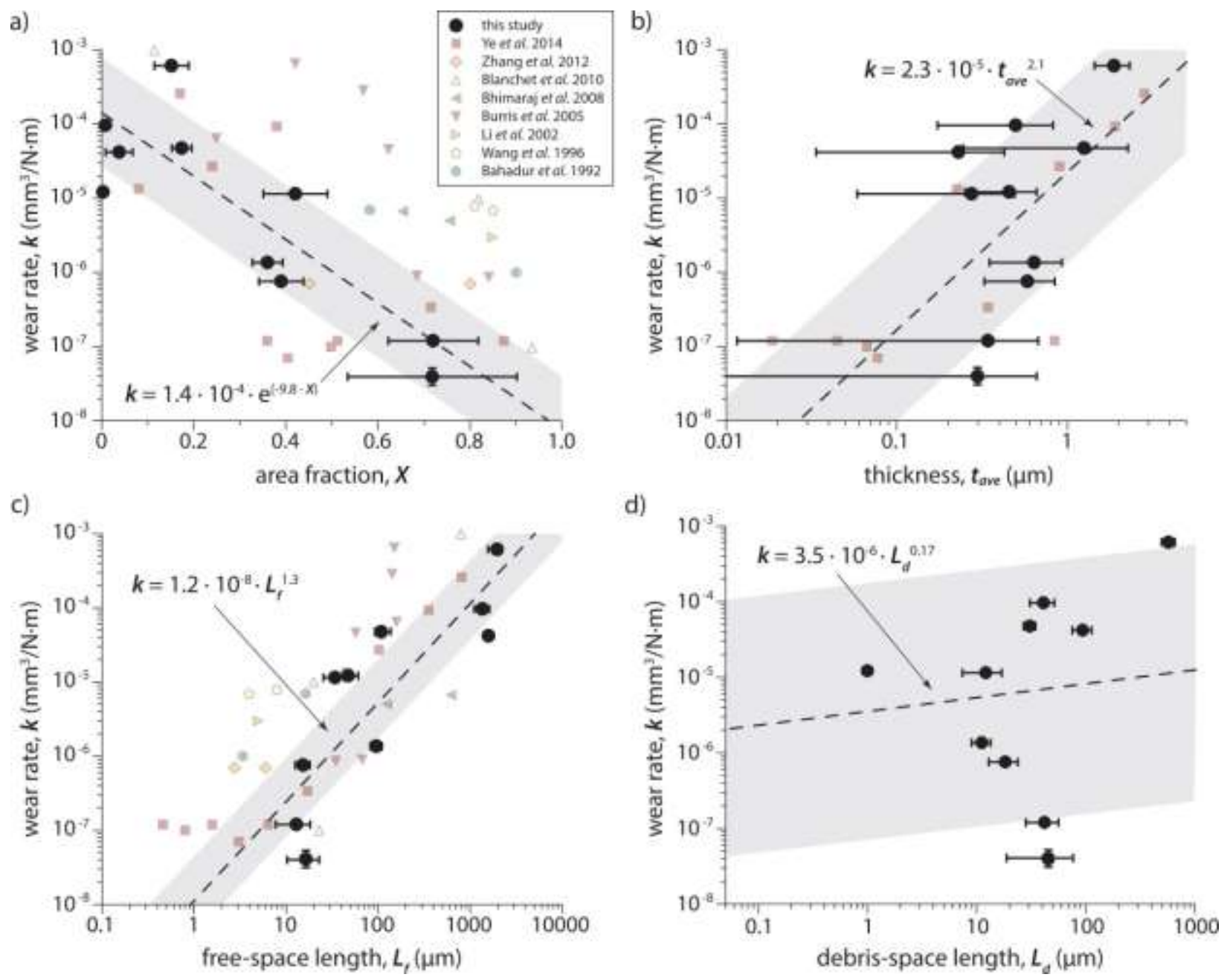

Figure 5. Wear rate versus transfer film: (a) area fraction $(X)$, (b) thickness $\left(t_{\text {ave }}\right)$, (c) free-space length $\left(L_{f}\right)$, and (d) debris-space length $\left(L_{d}\right)$. Results from Table 2 (black circles), the best-fit trendlines to the data from this study (dashed line), and the mean variation of these data from the trendline (grey shaded region) are shown in each image. Results extracted from prior studies of varying materials and testing conditions have been included in the background to test trend generality and trendline predictability for each metric $[9,11,16,19,34,35,37,38]$. 
Wear rate is plotted against transfer film area fraction, thickness, free-space length, and debrisspace length in Figure 5. Despite the large variation in properties of the materials included in this study, the expected relationships were generally maintained; wear rate tended to decrease with decreased thickness, increased area fraction, decreased free-space length, and decreased debris size. For the purpose of assessing fit quality, a difference in wear rate from 1 to $5 \times 10^{-4}$ was treated equivalently to a difference in wear rates from 1 and $5 \times 10^{-7}$. Because the coefficient of determination $\left(R^{2}\right)$, the more common measure of correlation strength, gives the former $1,000,000$ times more weight than the latter, we assess correlation strength based on the ratio (max/min) between measured values and model predictions. The grey region on each plot represents the best-fit \pm the uncertainty (standard deviation of the ratio). Wear rate correlated best with free-space length, with an uncertainty of 3.5x, and next-best with area fraction, with an uncertainty of $5.5 \mathrm{x}$. The correlation between wear rate and thickness produced an uncertainty of $15 \mathrm{x}$ and the correlation between wear rate and debris-space length produced an uncertainty of $50 x$.

\subsection{Discussion}

Numerous studies have drawn conclusions about the likely causal relationship between transfer film quality and wear rate based purely on the visual appearance of transfer films following steady state sliding [9-11,15,16,36]. Quantitative studies of transfer film morphology generally support these relationships, but they are often limited to a specific system of interest $[5,13,14,16,17]$. The variability within the system of interest is important. Laux and Schwartz showed that the apparent correlation between wear rate and transfer film thickness vanished when the molecular weight of their PEEK samples varied [20]. To our knowledge, the present study is the first to quantitatively test the link between wear rate and common transfer film morphology metrics for various representative polymers and polymer composites. Given the wide range of materials, properties, and wear rates of materials in this study, it is encouraging that the best-fits to wear rate based on the free-space length and area fraction were within $\sim 6 \mathrm{x}$ of the measured values.

The usefulness of these results depends on their ability to predict independent outcomes. A sampling of independent measurements from the literature has been included in Figure 5 to test 
predictability. One particularly interesting point of comparison is the study from Ye et al.[19], which involved the same 5\%wt. $\alpha$-phase alumina-PTFE sample from this study during the transition from run-in to steady state. As Figure 5 shows, the data from Ye et al. are wellrepresented by those of this study, which suggests that these relationships aren't entirely limited to steady state sliding. Applying the best-fits from this study to their results only slightly increases the uncertainties (from 3.5x to $8 \mathrm{x}$ and from $5.5 \mathrm{x}$ to $14 \mathrm{x}$ for free-space length and area fraction, respectively). The other data in Figure 5 are truly independent datasets with varying materials and tribological conditions; the best fits from this study applied to the independent results from the literature increases uncertainties to 24x (free-space length) and 305x (area fraction). The results consistently demonstrate that the free-space length is the best predictor of wear rate among the metrics considered in this study and, thus, provides the best independent measure of transfer film quality in the context of polymer wear.

The wear rate of all polymers should not be a single universal function of transfer film topology based on limit analysis. In the complete absence of a transfer film, such as during sliding in a single direction on straight line, unfilled PTFE would be expected to produce far higher wear rates than the other unfilled polymers in this study; hence, these polymers should all have unique upper limits (zero thickness, zero debris-space length, zero area fraction, infinite free-space length). Likewise, a similar system-dependent limit ought to exist at full transfer film coverage; the data from Ye et al. [19] in Figure 5c hints at such a lower limit near $10^{-7} \mathrm{~mm}^{3} / \mathrm{Nm}$. With this in mind, the degree to which the transfer film free-space length appears to reflect wear rates of different polymer system under varying testing conditions is all the more remarkable.

There is a relatively direct theoretical link between wear rate and free-space length. The freespace length governs the size of the mean adhesive zone and this size limits the size of the resulting debris. Furthermore, as the size of the adhesive zone shrinks, debris particle formation becomes less likely based on the balance between elastic energy and work of adhesion [40]. The area fraction is also directly related to wear rate since, at a given free-space length, the area fraction governs the number of adhesive zones. Although the free-space length tends to decrease with increased area fraction, the fact that the two are technically independent helps explain variations in measured wear rates about the trendlines based on these metrics. Although both 
metrics produced good fit quality based on our data, area fraction proved to be a less reliable predictor of wear rate based on independent measurements from the literature.

Interestingly, there are equally sound theoretical reasons why thickness and debris-space length ought to correlate strongly with wear rate. Thickness and debris-space length depend on debris size and shape. Decreased debris size implies smaller wear volumes and improved transfer film tenacity (due to the same competition between elastic energy and work of adhesion $[8,40]$ ). Nonetheless, wear rate measurements from this study were relatively poorly correlated to transfer film thickness and debris-space length. Results from Ye et al. [19] help reconcile the situation. They showed that transfer films of $\alpha$-phase alumina-PTFE developed through the growth and coalescence of nucleating debris fragments deposited early in the transition from runin to steady state; in other words, observable thickness and debris-space length at any point during steady do not necessarily reflect debris size and shape. Based on their results, the two low wear samples in the study likely produced debris fragments that were far smaller than the reported debris-space length of $50 \mu \mathrm{m}$; based on the study from Ye et al. [18] the debris size is probably closer to $100-500 \mathrm{~nm}$, in which case, the correlation between wear rate and debris size becomes vastly improved. The results suggest that, compared to the nature of the features of the transfer film itself, the nature of the areas devoid of transfer film (free-space and area fraction) provides a more direct link to polymer wear rates.

\subsection{Conclusion}

1. At steady state, wear rates of the 10 polymers and polymer composites included in this study spanned more than four orders of magnitude under moderate speed $(50 \mathrm{~mm} / \mathrm{s})$ and pressure $(6 \mathrm{MPa})$ conditions; the wear rate of unfilled PTFE ranked among the highest in the literature $\left(6 \times 10^{-4} \mathrm{~mm}^{3} / \mathrm{Nm}\right)$ and the wear rate of $30 \% \mathrm{wt}$. PEEK filled PTFE ranked among the lowest $\left(4 \times 10^{-8} \mathrm{~mm}^{3} / \mathrm{Nm}\right)$.

2. As wear rates decreased, transfer films became qualitatively thinner and better covered with domains of decreasing length-scale; these observations are consistent with those in many prior studies of the relationship between wear rate and the visual attributes of transfer films.

3. The transfer film free-space length provided the best correlation with wear rates from this study; the characteristic error between the fit and the data was $3.5 \mathrm{x}$. The area fraction 
provided similar fit quality with a characteristic error of 5.5x. By comparison, thickness and debris-space length were poorly correlated with wear rate; the characteristic errors between best-fit and data were 15x and 50x, respectively.

4. The free-space length was the most reliable independent predictor of wear rates. The best-fit based on free-space length predicted wear rates from independent studies in the literature with an uncertainty of $\sim 24 \mathrm{x}$. The uncertainty increased to $\sim 300 \mathrm{x}$ when the bestfit based on area fraction was used to predict the same wear rates.

5. To our knowledge, this is the first study to test the general relationships between polymer wear rates and transfer film morphology using a wide range of representative polymers and polymer composites. The results suggest that the free-space length provides the best independent measure of transfer film quality in the context of polymer wear.

\section{Acknowledgements}

The authors gratefully acknowledge financial support from the AFOSR (YIP FA9550-10-10295), the National Science Foundation Graduate Research Fellowship (124d7394), and the National Natural Science Foundation of China (51505117). The authors also thank Dr. Jing Qu for conducting the DSC measurements for polymer thermal characterization.

\section{Reference}

[1] W.G. Sawyer, N. Argibay, D.L. Burris, B.A. Krick, Mechanistic Studies in Friction and Wear of Bulk Materials, Annu. Rev. Mater. Res. 44 (2014) 395-427. doi:10.1146/annurev-matsci-070813113533.

[2] D.L. Burris, B. Boesl, G.R. Bourne, W.G. Sawyer, Polymeric Nanocomposites for Tribological Applications, Macromol. Mater. Eng. 292 (2007) 387-402. doi:10.1002/mame.200600416.

[3] S. Bahadur, D. Tabor, The wear of filled polytetrafluoroethylene, Wear. 98 (1984) 1-13. doi:10.1016/0043-1648(84)90213-8.

[4] E.E. Nunez, A.A. Polycarpou, The effect of surface roughness on the transfer of polymer films under unlubricated testing conditions, Wear. 326-327 (2015) 74-83. doi:10.1016/j.wear.2014.12.049.

[5] V. Rodriguez, J. Sukumaran, A.K. Schlarb, P. De Baets, Reciprocating sliding wear behaviour of PEEK-based hybrid composites, Wear. 362-363 (2016) 161-169. doi:10.1016/j.wear.2016.05.024.

[6] Y. Wang, F. Yan, Tribological properties of transfer films of PTFE-based composites, Wear. 261 (2006) 1359-1366. doi:10.1016/j.wear.2006.03.050.

[7] Y. Wang, F. Yan, A study on tribological behaviour of transfer films of PTFE/bronze composites, Wear. 262 (2007) 876-882. doi:10.1016/j.wear.2006.08.026.

[8] J. Ye, A.C. Moore, D.L. Burris, Transfer Film Tenacity: A Case Study Using Ultra-Low-Wear Alumina-PTFE, Tribol. Lett. 59 (2015) 1-11. doi:10.1007/s11249-015-0576-4. 
[9] Q. Wang, Q. Xue, H. Liu, W. Shen, J. Xu, The effect of particle size of nanometer ZrO2 on the tribological behaviour of PEEK, Wear. 198 (1996) 216-219. doi:10.1016/0043-1648(96)07201-8.

[10] Q.-H. Wang, J. Xu, W. Shen, Q. Xue, The effect of nanometer SiC filler on the tribological behavior of PEEK, Wear. 209 (1997) 316-321. doi:10.1016/S0043-1648(97)00015-X.

[11] F. Li, K. Hu, J. Li, B. Zhao, The friction and wear characteristics of nanometer ZnO filled polytetrafluoroethylene, Wear. 249 (2001) 877-882. doi:10.1016/S0043-1648(01)00816-X.

[12] W.G. Sawyer, K.D. Freudenberg, P. Bhimaraj, L.S. Schadler, A study on the friction and wear behavior of PTFE filled with alumina nanoparticles, Wear. 254 (2003) 573-580. doi:10.1016/S0043-1648(03)00252-7.

[13] P. Bhimaraj, D.L. Burris, J. Action, W.G. Sawyer, C.G. Toney, R.W. Siegel, L.S. Schadler, Effect of matrix morphology on the wear and friction behavior of alumina nanoparticle/poly(ethylene) terephthalate composites, Wear. 258 (2005) 1437-1443. doi:10.1016/j.wear.2004.09.077.

[14] S. Bahadur, C. Sunkara, Effect of transfer film structure, composition and bonding on the tribological behavior of polyphenylene sulfide filled with nano particles of $\mathrm{TiO} 2, \mathrm{ZnO}, \mathrm{CuO}$ and SiC, Wear. 258 (2005) 1411-1421. doi:10.1016/j.wear.2004.08.009.

[15] N.L. McCook, B. Boesl, D.L. Burris, W.G. Sawyer, Epoxy, ZnO, and PTFE nanocomposite: friction and wear optimization, Tribol. Lett. 22 (2006) 253-257. doi:10.1007/s11249-006-9089-5.

[16] D.L. Burris, W.G. Sawyer, Tribological Sensitivity of PTFE/Alumina Nanocomposites to a Range of Traditional Surface Finishes, Tribol. Trans. 48 (2005) 147-153. doi:10.1080/05698190590923842.

[17] K.A. Laux, C.J. Schwartz, Influence of linear reciprocating and multi-directional sliding on PEEK wear performance and transfer film formation, Wear. (2013). doi:10.1016/j.wear.2012.12.004.

[18] J. Ye, H.S. Khare, D.L. Burris, Transfer film evolution and its role in promoting ultra-low wear of a PTFE nanocomposite, Wear. 297 (2013) 1095-1102. doi:10.1016/j.wear.2012.12.002.

[19] J. Ye, H.S. Khare, D.L. Burris, Quantitative characterization of solid lubricant transfer film quality, Wear. 316 (2014) 133-143. doi:10.1016/j.wear.2014.04.017.

[20] K.A. Laux, C.J. Schwartz, Effects of contact pressure, molecular weight, and supplier on the wear behavior and transfer film of polyetheretherketone (PEEK), Wear. 297 (2013) 919-925. doi:10.1016/j.wear.2012.11.013.

[21] B.A. Krick, A.A. Pitenis, K.L. Harris, C.P. Junk, W.G. Sawyer, S.C. Brown, H.D. Rosenfeld, D.J. Kasprzak, R.S. Johnson, C.D. Chan, G.S. Blackman, Ultralow wear fluoropolymer composites: Nanoscale functionality from microscale fillers, Tribol. Int. 95 (2016) 245-255. doi:10.1016/j.triboint.2015.10.002.

[22] D.L. Burris, W.G. Sawyer, Improved wear resistance in alumina-PTFE nanocomposites with irregular shaped nanoparticles, Wear. 260 (2006) 915-918. doi:10.1016/j.wear.2005.06.009.

[23] S.E. McElwain, T.A. Blanchet, L.S. Schadler, W.G. Sawyer, Effect of Particle Size on the Wear Resistance of Alumina-Filled PTFE Micro- and Nanocomposites, Tribol. Trans. 51 (2008) 247-253. doi:10.1080/10402000701730494.

[24] B.A. Krick, J.J. Ewin, G.S. Blackman, C.P. Junk, W. Gregory Sawyer, Environmental dependence of ultra-low wear behavior of polytetrafluoroethylene (PTFE) and alumina composites suggests tribochemical mechanisms, Tribol. Int. 51 (2012) 42-46. doi:10.1016/j.triboint.2012.02.015.

[25] A.A. Pitenis, J.J. Ewin, K.L. Harris, W.G. Sawyer, B.A. Krick, In Vacuo Tribological Behavior of Polytetrafluoroethylene (PTFE) and Alumina Nanocomposites: The Importance of Water for Ultralow Wear, Tribol. Lett. 53 (2014) 189-197. doi:10.1007/s11249-013-0256-1.

[26] D.L. Burris, W.G. Sawyer, A low friction and ultra low wear rate PEEK/PTFE composite, Wear. 261 (2006) 410-418. doi:10.1016/j.wear.2005.12.016.

[27] N.L. McCook, M.A. Hamilton, D.L. Burris, W.G. Sawyer, Tribological results of PEEK nanocomposites in dry sliding against 440C in various gas environments, Wear. 262 (2007) 15111515. doi:10.1016/j.wear.2007.01.036.

[28] D.L. Burris, W.G. Sawyer, Measurement Uncertainties in Wear Rates, Tribol. Lett. 36 (2009) 8187. doi:10.1007/s11249-009-9477-8. 
[29] K.R. Makinson, D. Tabor, The Friction and Transfer of Polytetrafluoroethylene, Proc. R. Soc. Math. Phys. Eng. Sci. 281 (1964) 49-61. doi:10.1098/rspa.1964.0168.

[30] K. Tanaka, S. Kawakami, Effect of various fillers on the friction and wear of polytetrafluoroethylene-based composites, Wear. 79 (1982) 221-234. doi:10.1016/00431648(82)90170-3.

[31] T.A. Blanchet, F.E. Kennedy, Sliding wear mechanism of polytetrafluoroethylene (PTFE) and PTFE composites, Wear. 153 (1992) 229-243. doi:10.1016/0043-1648(92)90271-9.

[32] J.M. Urueña, A.A. Pitenis, K.L. Harris, W.G. Sawyer, Evolution and Wear of Fluoropolymer Transfer Films, Tribol. Lett. 57 (2015). doi:10.1007/s11249-014-0453-6.

[33] A.A. Pitenis, K.L. Harris, C.P. Junk, G.S. Blackman, W.G. Sawyer, B.A. Krick, Ultralow Wear PTFE and Alumina Composites: It is All About Tribochemistry, Tribol. Lett. 57 (2015). doi:10.1007/s11249-014-0445-6.

[34] P. Bhimaraj, D. Burris, W.G. Sawyer, C.G. Toney, R.W. Siegel, L.S. Schadler, Tribological investigation of the effects of particle size, loading and crystallinity on poly(ethylene) terephthalate nanocomposites, Wear. 264 (2008) 632-637. doi:10.1016/j.wear.2007.05.009.

[35] G. Zhang, R. Sebastian, T. Burkhart, K. Friedrich, Role of monodispersed nanoparticles on the tribological behavior of conventional epoxy composites filled with carbon fibers and graphite lubricants, Wear. 292-293 (2012) 176-187. doi:10.1016/j.wear.2012.05.012.

[36] Q. Zhao, S. Bahadur, A study of the modification of the friction and wear behavior of polyphenylene sulfide by particulate Ag2S and PbTe fillers, Wear. 217 (1998) 62-72. doi:10.1016/S0043-1648(98)00155-0.

[37] T.A. Blanchet, S.S. Kandanur, L.S. Schadler, Coupled Effect of Filler Content and Countersurface Roughness on PTFE Nanocomposite Wear Resistance, Tribol. Lett. 40 (2010) 11-21. doi:10.1007/s11249-009-9519-2.

[38] S. Bahadur, D. Gong, J.W. Anderegg, The role of copper compounds as fillers in transfer film formation and wear of nylon, Wear. 154 (1992) 207-223. doi:10.1016/0043-1648(92)90155-2.

[39] H.S. Khare, A.C. Moore, D.R. Haidar, L. Gong, J. Ye, J.F. Rabolt, D.L. Burris, Interrelated Effects of Temperature and Environment on Wear and Tribochemistry of an Ultralow Wear PTFE Composite, J. Phys. Chem. C. 119 (2015) 16518-16527. doi:10.1021/acs.jpcc.5b00947.

[40] E. Rabinowicz, Friction and Wear of Materials, Wiley, New York, 1995. 